\title{
Myocardial Function and Lipid Metabolism in the Chronic Alcoholic Animal
}

\author{
Timothy J. Regan, Mohammad I. Khan, Philip O. Ettinger, Bunyad Haider, \\ Michael M. Lyons, and Henry A. Oldewurtel with the technical \\ assistance of MARILYN WEBER
}

From the Department of Medicine, College of Medicine and Dentistry-New Jersey Medical School, Newark, New Jersey 07103

A B STRACT In view of the variables that obscure the pathogenesis of cardiomyopathy, a study was undertaken in mongrel dogs fed ethanol as $36 \%$ of calories for up to 22 mo. Both the experimental and control groups maintained body weight, hematocrit, plasma vitamin, and protein levels. Left ventricular function was evaluated in the intact anesthetized dog using indicator dilution for end-diastolic and stroke volume determinations. During increased afterload with angiotensin, the ethanol group exhibited a larger rise of end-diastolic pressure $(P<0.01)$, whereas end-diastolic and stroke volume responses were significantly less than in controls. Preload increments with saline elicited a significantly higher end-diastolic pressure rise in the ethanol group $(P<0.01)$. No hypertrophy, inflammation, or fibrosis was present and it was postulated that the enhanced diastolic stiffness was related to accumulation of Alcian Blue-positive material in the ventricular interstitium.

To evaluate myocardial lipid metabolism, $\left[1-{ }^{14} \mathrm{C}\right]$ oleic acid was infused systemically. Plasma specific activity and myocardial lipid uptake were similar in both groups. There was a significantly increased incorporation of label into triglyceride, associated with a reduced ${ }^{14} \mathrm{CO}_{2}$ production, considered the basis for a twofold increment of triglyceride content. In addition, diminished incorporation of $\left[{ }^{14} \mathrm{C}\right]$ oleic acid into phospholipid was observed accompanied by morphologic abnormalities of cardiac cell membranes. Potassium loss and sodium gain, like the lipid alteration, was more prominent in the subendocardium. Thus, chronic ethanol ingestion in this animal model is associated with abnormalities of ventricular function without evident malnutrition, analogous to the preclinical malfunction described in the human alcoholic.

Received for publication 8 October 1973 and in revised form 20 May 1974.

\section{INTRODUCTION}

Several clinical studies have suggested that chronic use of ethyl alcohol in large quantities is associated with disease of cardiac muscle $(1,2)$. While histologic abnormalities have been observed in $90 \%$ of unselected alcoholics at postmortem (3), uncertainty as to the quantity of ethanol intake, the nutritional status of the patient including electrolyte deficits, and the potential contribution of viral or coronary artery disease have obscured an understanding of the pathogenesis of this cardiomyopathy. This study was undertaken to evaluate the effects of chronic ethanol intake in healthy mongrel dogs, a species in which the complicating factor of spontaneous coronary atherosclerosis is virtually excluded in the young adult.

These animals were maintained in a relatively normal nutritional state while receiving up to $36 \%$ of calories as ethanol, approximating the quantity reported in a population of human alcoholics (4). After an average of 18 mo observation when evaluation of nutritional status included assay of plasma vitamins, the chronic ethanol and control animals were anesthetized to evaluate left ventricular performance and morphology. Since myocardial lipid alterations have been reported after chronic ethanol intake $(5,6)$, the myocardial metabolism of $\left[1-{ }^{14} \mathrm{C}\right]$ oleic acid has also been assessed.

\section{METHODS}

Male mongrel dogs, 2-3 yr of age, were selected from animals in good health and divided into a control group of 10 and a chronic ethanol group of 13. All were vaccinated against distemper, hepatitis, and leptospirosis, and were housed in individual cages. They were free of intestinal parasites and clinical evidence of disease for a period of 6-8 wk of observation before admission to the study. Blood samples were negative for heart worms and both hematocrit and serum proteins were initially normal. One 
animal from the control group was found to have heart worms at autopsy and was excluded from the study.

Both the control and experimental animals were fed approximately $28 \mathrm{cal} / \mathrm{lb}$, consisting of a mixture of Blue Ribbon Beef Dog Food (Deep Rung Packing Co., Dublin, $\mathrm{Pa}$.) and Kibble (Old Mother Hubbard Dog Food Co., Inc., Gloucester, Mass.) in a one to three ratio. The controls received a diet sufficient to maintain body weight in the adult animal (7), consisting of $26 \%$ of calories as protein, $12 \%$ fat, and $62 \%$ carbohydrate. The corresponding values in the alcoholic group were $16.6 \%$ of calories as protein, $7.7 \%$ lipid, and $39.7 \%$ carbohydrate, which met the minimum standard for maintaining a normal nutritional state $(7)$. Both groups received a vitamin supplement twice weekly, Folbesyn (generously supplied by Dr. William Sweeney, Director of Medical Research, Lederle Laboratories, Pearl River, N. Y.) i.m. The total vitamin dosage per week included thiamine $\mathrm{HCl} 5 \mathrm{mg}$, riboflavin $5 \mathrm{mg}$, niacin $35 \mathrm{mg}$, pyridoxine $\mathrm{HCl} 2.5 \mathrm{mg}$, ascorbic acid $150 \mathrm{mg}, \mathrm{B}_{12} 2 \mu \mathrm{g}$, sodium pantothenate $5 \mathrm{mg}$, and folic acid $1.5 \mathrm{mg}$.

Atter $4 \mathrm{wk}$ of progressively increasing doses, animals consuming virtually all the ethanol provided were admitted to the experimental group. The chronic ethanol animals were provided $36 \%$ of calories as ethyl alcohol for 6 days/wk. On the 7th day, the caloric composition was the same as the control group. Due to the difficulties of feeding by gastric tube for a prolonged period, the ethanol (USP, Acquired from U. S. Industrial Chemicals, Div. of National Distillers \& Chemical Corp., New York.) was administered in drinking water up to a final concentration of $40 \%$. The actual intake per animal was estimated by measuring the residual ethanol solution of the previous day, correcting for evaporation from a separate container. The intake of each animal remained relatively constant but varied between animals, from $70 \%$ of the administered dose in some to $100 \%$ in others.

In both groups of animals, two venous blood samples were taken $4 \mathrm{wk}$ apart at the onset of the study and at intervals of 2 mo thereafter, for determination of plasma lipids. Blood was placed in chilled tubes containing EDTA and after separation in a refrigerated centrifuge, stored at $-20^{\circ} \mathrm{C}$ before analysis. Determinations were done in duplicate and included free fatty acid (8), triglyceride (9), phospholipid (10), cholesterol (11), and glucose (12). In addition, hematocrit, serum protein (13), and albumin (14) were determined. At the terminal study blood samples were taken for analyses of vitamins of the $B$ series as well as vitamin $\mathrm{A}, \mathrm{C}$, and $\mathrm{E}$ (15). (Performed as unknowns in the laboratory of Dr. Herman Baker through the courtesy of Dr. Carroll Leevy, Division of Hepatology.)

After an observation period of 8-20 mo for the control group, six animals had metabolic studies and eight were assessed hemodynamically. After 9-22 mo of ethanol intake in the experimental group, six animals had metabolic studies and seven hemodynamic evaluation. From the original group of 13,4 were studied post-mortem after expiring unexpectedly in their cage. All animals were anesthetized with $3 \mathrm{mg} / \mathrm{kg}$ of morphine and $12 \mathrm{mg} / \mathrm{kg}$ of Nembutal and ventilated to maintain arterial oxygen saturation and $\mathrm{pH}$ in the normal range. To minimize the acute influence of the last administered dose, the experimental group did not receive ethanol for the previous $38 \mathrm{~h}$. Each animal in all groups was provided its regular diet on the previous afternoon and feeding was completed by 6:00 p.m. Anesthesia was induced at 8:00 a.m. and a supplementary dose of 50 my was administered between $9: 30$ and 10:00 a.m. to facilitate respiratory control.

Hemodynamic studies. Ejection fraction levels are usually reduced after this anesthesia (16) to approximately $50 \%$ of those found in unanesthetized dogs (17). However, a relatively steady hemodynamic state appears to be present approximately $3 \mathrm{~h}$ after anesthetic induction when our studies were undertaken, since further decline of cardiac output after pentobarbital is usually not observed (18). In view of the fact that ventricular function was assessed in control and experimental animals at approximately the same time, variations due to anesthesia would presumably affect both control and experimental groups similarly.

Catheters were placed in the pulmonary artery, left ventricle, and root of the descending aorta and maintained patent by infusion or intermittent flushing with small volumes of saline; no glucose was given. The $50-\mathrm{cm}$ GoodaleLubin $8 \mathrm{~F}$ catheters were connected directly to Statham strain gauge transducers $\mathrm{P} 23 \mathrm{Db}$ (Statham Instruments, Inc., Oxnard, Calif.). Photographic recordings were made from a multichannel oscilloscope recorder (Electronics for Medicine, Inc., White Plains, N. Y.). The frequency of this recording system was linear from 0 to 30 cycles/s. The first derivative of the left ventricular pressure pulse $(\mathrm{d} p / \mathrm{d} t)$ was computed continuously by an R-C differentiating circuit and converted into millimeters of mercury per second. The amplitude of $\mathrm{d} p / \mathrm{d} t$ was a linear function of frequency to $70 \mathrm{cycles} / \mathrm{s}$. Ventricular diastolic pressure was recorded at sufficient sensitivity so that $1 \mathrm{~mm} \mathrm{Hg}$ equaled $5 \mathrm{~mm}$ on the tracing. All measurements were made at the end-expiration phase of the respiratory cycle; the average of six separate determinations were taken.

Cardiac output and left end-diastolic ventricular volume were determined by the dye dilution technique using indocyanine green (19), a Gilford model 103-IR Densitometer (Gilford Instrument Laboratories Inc., Oberlin, Ohio), and a withdrawal pump for sampling blood from the aortic root (Harvard Apparatus Co., Inc., Millis, Mass.). In a previous report by colleagues from our laboratory, left ventricular ejection fraction by the dye dilution technique has shown good reproducibility in a hydraulic model under nearly ideal conditions of mixing and sampling, with a mean coefficient of variation of $3 \%$ (19). An in vivo study of ejection fraction in the dog compared favorably, with a coefficient of variation of $6 \%$ (19). While an absolute test of accuracy in vivo is not available, three studies comparing the indicator dilution technique with independent methods have shown good agreement (20-22). The study by Swan, Ganz, Wallace, and Tanura (21) represents a revision of a previous conclusion that the indicator dilution technique differed substantially from angiographic data (23).

Accurate measurement of end-diastolic volume in the right ventricle has been difficult, presumably due to inflow patterns which promote nonmixing (24). To determine if satisfactory mixing occurs in the left ventricle of the normal intact anesthetized dog, we have compared sequential ejection fractions after fluoroscopic placement of a Goodale-Lubin catheter in different locations of the left ventricle for injection of $5 \mathrm{ml}$ of dye in normal saline. Each ventricular location was compared with the left atrial injection site, which is assumed to provide complete mixing of dye with ventricular chamber blood, since identical indicator dilution downstroke slopes have been obtained after injections into either chamber of an atrioventricular 
model (25). In addition, a previous study comparing left ventricular end-diastolic volume measurements during injection of thermal indicator into left atrium or ventricle of the intact dog, revealed a correlation coefficient of 0.98 between these two injection sites (17). For this study with indocyanine green, the catheter was withdrawn after four atrial injections and placed at the apex of the ventricle for four determinations. The atrial injections were repeated and the catheter placed in the mid-ventricle at the level of the inflow tract. After a third atrial run, dye was injected into the upper third of the ventricular chamber in the outflow tract.

Serial comparisons were made only if heart rate and aortic pressure were comparable. The mean ejection fraction in three normal animals after left atrial injections was $29.7 \pm 2.3$ compared to $28.3 \pm 2.2 \%$ after green dye was injected at the left ventricular apex. The correlation coefficient was 0.97 for 12 comparisons. Injection of dye at the inflow site revealed an ejection fraction of $27.8 \pm 2.3$ compared to $29.2 \pm 3.0 \%$ in the previous left atrial injections, with a correlation coefficient of 0.94 . The mean ejection fraction after injection at the outflow tract was $35 \pm 7.1$ compared to $30.3 \pm 1.6 \%$ in the prior left atrial determinations. The correlation coefficient for the 12 comparisons was 0.34. These data indicate that the requirement for adequate mixing of dye with blood in the ventricle is met by injections at the level of the inflow tract, which was the site used in these studies of alcoholic animals. The apical location was not used to preclude possible tissue injury with a catheter in close proximity to endocardium. We conclude that the differences in end-diastolic volume in response to afterload increments are real since the least favorable comparison of the indicator and angiographic measurements has indicated that both methods reflect the same directional change during acute interventions (26).

The end-diastolic volume, derived from ejection fraction and stroke volume measurements is expressed as per kilogram since a linear relation to body weight has been reported in a wide range of mammals (27). Stroke work of the ventricle in gram meters per kilogram was calculated from the formula SV $\times($ LVES-LVED) $\times 1.36$ in which $\mathrm{SV}=$ the stroke volume in milliliters; $\mathrm{LVES}=$ the mean left ventricular pressure during ejection in millimeters of mercury; LVED = left ventricular end-diastolic pressure in millimeters of mercury.

As an approximation of the inotropic state of the ventricle, we have used the peak $\mathrm{d} p / \mathrm{d} t$, normalized in view of its dependency upon the loading conditions of the myocardium, as well as on the contractile state. This index of contractility (28) is expressed as $(\mathrm{d} p / \mathrm{d} t / M I P) / 2 \pi r: \mathrm{d} p / \mathrm{d} t$, the maximum rate of left ventricular pressure rise is usually the principal parameter altered during contractility change; MIP, the maximum isovolumic pressure, is a linear function of tension during the systolic isovolumic period; $2 \pi r$ is the circumferential fiber-length used to normalize the index for hearts of different size, in which the radius is derived from the end-diastolic volume measurement.

To assess left ventricular function in intact animals without evidence of cardiac abnormality at rest, we have increased afterload moderately by raising aortic diastolic pressure with angiotensin. This has provided a relatively sensitive test of cardiac function in normal humans, producing an increment of a few millimeters of mercury in ventricular end-diastolic pressure and a modest stroke work increase, a response which is altered by subclinical disease $(29,30)$. In a study of intact anesthetized dogs these changes were also associated with a moderate enddiastolic volume elevation (31). The afterload increment in the normal dogs of this study is of the same order as these previous reports; we have avoided the larger, more rapid increments which may have a different effect on the end-diastolic pressure-volume relationship in normals (32). After paired determinations of hemodynamic parameters in the basal state, an intravenous injection of angiotensin in saline was begun to evaluate ventricular function during afterload increments. The dosage was adjusted until a sustained aortic diastolic pressure increase of approximately 16 $\mathrm{mm} \mathrm{Hg}$ was present after 10-15 min of infusion, at which time duplicate measurements of cardiac output, ventricular end-diastolic volume, and pressures were obtained. The dose of angiotensin at the time of the hemodynamic studies in the control group averaged $2.6 \mu \mathrm{g} / \mathrm{min}$ in the control and $2.7 \mu \mathrm{g} / \mathrm{min}$ in the ethanol group.

We have further assessed the end-diastolic pressurevolume relationship by volume increments. In the intact anesthetized dogs $50 \mathrm{ml} / \mathrm{min}$ of normal saline was infused into the left ventricle for 3-4 min via a polyethylene catheter passed from the aorta in six experimental and six control animals. In a separate group of five acute animals, this intervention did not induce mitral regurgitation as determined by ventricular angiography. At the conclusion of the hemodynamic studies a supplementary dose of $50 \mathrm{mg}$ of Nembutal was administered to each animal.

Metabolic studies. After an interval of approximately $2 \mathrm{~h}, 300 \mu \mathrm{Ci}$ of $\left[{ }^{14} \mathrm{C}-1\right]$ oleic acid $(57 \mu \mathrm{Ci} / \mathrm{mmol})$ was infused into the inferior vena cava in six control and six chronic ethanol animals. The isotopic fatty acid was previously processed by preparative thin-layer chromatography to a radiochemical purity of greater than $99 \%$. Albuminbound oleic acid was prepared by dissolving the fatty acid in ethyl alcohol, adding 2 meq of potassium carbonate in water and evaporating to dryness with gentle heat and a stream of nitrogen gas. The residue was immediately dissolved in warm water at $\mathrm{pH} 7.6$ and human albumin was slowly added, resulting in a fatty acid to albumin ratio of approximately 2 . When at room temperature, the $\mathrm{pH}$ of the mixture was maintained at 7.4. Before the infusion of oleic acid, $100 \mu \mathrm{Ci}$ of ${ }^{80} \mathrm{Kr}$ saline was injected retrograde into the coronary sinus through a Goodale-Lubin catheter to determine coronary blood flow by the clearance method (33), for calculation of substrate uptake.

The oleic acid was infused continuously for $20 \mathrm{~min}$ after an initial priming dose. ${ }^{14} \mathrm{C}$ activity in plasma was constant after $6-8 \mathrm{~min}$ and no recirculation in other plasma lipids was observed as previously reported (34). Arterial-coronary sinus blood samples were taken at $9,13,16$, and 19 min of the infusion, in syringes coated with oil and capped for ${ }^{14} \mathrm{CO}_{2}$ determination (35). Separate samples were taken for substrate analysis. Disodium EDTA was the anticoagulant.

At the conclusion of the oleic acid infusion, the heart was rapidly arrested with iced Ringers solution. Approximately 15-g samples of the left ventricle were taken from the periapical region. In view of the potential heterogeneity of the myocardial metabolic response (36), the ventricle was divided into inner, mid, and outer layers, the latter carefully trimmed to remove epicardial adipose tissue, and quickly placed in liquid nitrogen. This method of cooling appeared to be sufficiently rapid to minimize lipolysis as compared with a biopsy technique. Four normal anesthetized dogs had approximately $600-\mathrm{mg}$ transmural 
samples removed by biopsy and placed in liquid nitrogen within $3 \mathrm{~s}$, and the free fatty acid content compared with samples processed as outlined above. The free fatty acid levels in the four biopsy samples were $8.9 \pm 0.4$ and $9.2 \pm 0.5$ $\mu \mathrm{M} / \mathrm{g}$ in the four processed samples.

Separate portions of the tissue samples were homogenized in a volume of distilled water three times the tissue weight. Portions of these homogenates were reserved for analysis of potassium and sodium using a Technicon AutoAnalyzer system with flame attachment (Technicon Instruments Corp., Tarrytown, N. Y.). Water content was calculated from the wet weight-dry weight difference after drying in an oven for $18 \mathrm{~h}$ at $110^{\circ} \mathrm{C}$.

The plasma and tissue homogenates were extracted by the Folch procedure and the extract washed with acid buffer. A portion of the chloroform extract was evaporated in a liquid scintillation vial and used to determine total lipid radioactivity in the original sample. A second aliquot of the chloroform extract was concentrated for separation of lipid classes by thin-layer chromatography (37). Identified spots from all thin-layer plates were scraped into miniature funnels with the aid of suction and eluted with chloroform: methyl alcohol $(2: 1)$ into liquid scintillation vials for assay of radioactivity. The sum of the radioactivity in the eluted areas averaged $78 \%$ of the total radioactivity found in the original extract. The difference is due to losses in evaporative concentration, pipetting and radioactivity distributed in areas of the plate not eluted.

The third part of the washed lipid extract was concentrated and applied to a silicic acid column, which was pretreated by washing with $1 \%$ acetic acid in chloroform solution. The first elution of the column included triglycerides, free fatty acids, cholesterol and its esters, which were quantitatively recovered as determined by recovery of ${ }^{14} \mathrm{C}$-labeled lipids. An aliquot of this chloroform eluate was evaporated, replaced with isopropyl alcohol and analyzed simultaneously for cholesterol and triglycerides on the Technicon AutoAnalyzer. The column was subse- quently eluted with methyl alcohol to obtain the phospholipid fraction. A portion of this fraction was evaporated and digested in an oven with sulfuric acid and hydrogen peroxide to liberate inorganic phosphate for assay. All ${ }^{14} \mathrm{C}$ radioactivity measurements were performed on a NuclearChicago liquid scintillation counter (Nuclear-Chicago Corp., Des Plaines, Ill.) at room temperature. 0.5\% 2,5-diphenyloxazole and $0.03 \% p$-1,4-bis[2-(5-phenyloxazolyl)]benzene in toluene were used for the scintillator. Absolute activities were calculated using quenched standards and a channelsratio method. All statistical data in this study are presented as standard errors of the mean. Nonpaired or paired $t$ tests were used as appropriate (38).

Sections were taken from the left ventricular myocardium and left coronary artery for histochemical examination by the pathologist without knowledge of animal identification. These included periodic acid-Schiff after twice pretreating with diastase to exclude staining of glycogen (39), Alcian Blue at three acid $\mathrm{pH}$ levels (40), and Oil Red 0 (40). Specimens for electron microscopy were fixed in cold glutaraldehyde buffered with phosphate. The tissue was then washed, postfixed in osmium, exposed to lead and uranyl acetate, and imbedded in epon.

\section{RESULTS}

While consuming an average of $3.11 \pm 0.24 \mathrm{~g}$ of etha$\mathrm{nol} / \mathrm{kg}$ daily, the nutritional status of the experimental animals was quite comparable to the controls (Table I). In addition to a small weight gain that was similar for both groups by the conclusion of the study, the hematocrit, serum protein, and fasting blood glucose in the unanesthetized state remained at control levels. Further, serum albumin determination at the end of the study averaged $3.5 \pm 0.2 \mathrm{~g} / 100 \mathrm{ml}$ in five of the controls and $3.4 \pm 0.1$ in five experimental animals.

TABLE I

Nutritional Status

\begin{tabular}{|c|c|c|c|c|}
\hline & \multicolumn{2}{|c|}{ Controls $(n=10)$} & \multicolumn{2}{|c|}{ Ethanol group $(n=9)^{*}$} \\
\hline & Initial & Terminal & Initial & Terminal \\
\hline Weight, $k g$ & $25.1 \pm 0.5$ & $26.8 \pm 0.4$ & $25.9 \pm 0.9$ & $27.1 \pm 0.7$ \\
\hline Hematocrit & $45 \pm 0.4$ & $44 \pm 0.3$ & $46 \pm 0.5$ & $47 \pm 0.6$ \\
\hline Serum protein, $\mathrm{g} / 100 \mathrm{ml}$ & $7.9 \pm 0.3$ & $7.7 \pm 0.4$ & $7.6 \pm 0.2$ & $7.8 \pm 0.4$ \\
\hline Fasting blood glucose, $\mathrm{mg} / 100 \mathrm{ml}$ & $79 \pm 3$ & $82 \pm 4$ & $84 \pm 2$ & $87 \pm 3$ \\
\hline \multicolumn{5}{|l|}{ Vitamins } \\
\hline $\mathrm{A}, \mu g / 100 \mathrm{ml}$ & & $130 \pm 18.9$ & & $102 \pm 13.9$ \\
\hline Thiamine, $n g / m l$ & & $53 \pm 8.1$ & & $52 \pm 6.6$ \\
\hline Riboflavin, $n g / m l$ & & $295 \pm 54$ & & $246 \pm 46$ \\
\hline Niacin, $\mu g / m l$ & & $4.6 \pm 0.54$ & & $5.9 \pm 1.34$ \\
\hline Pyridoxine, $n g / m l$ & & $37 \pm 5.2$ & & $48.8 \pm 14.7$ \\
\hline Pantothenic acid, $n g / m l$ & & $94.2 \pm 4.9$ & & $118 \pm 13.1$ \\
\hline $\mathrm{B}_{12}, \mu \mathrm{g} / \mathrm{ml}$ & & $100 \pm 21.3$ & & $119 \pm 37.3$ \\
\hline Folic acid, $n g / m l$ & & $9.65 \pm 2.9$ & & $7.25 \pm 1.98$ \\
\hline Biotin, $n g / m l$ & & $1,189 \pm 218$ & & $1,039 \pm 184$ \\
\hline C, $m g / 100 m l$ & & $0.66 \pm 0.18$ & & $0.58 \pm 0.21$ \\
\hline $\mathrm{E}, m g / 100 m l$ & & $0.33 \pm 0.06$ & & $0.31 \pm 0.09$ \\
\hline
\end{tabular}

* Does not include four who died unexpectedly. 
TABLE II

Left Ventricular Response to Afterload Increase

\begin{tabular}{|c|c|c|c|c|c|c|c|c|c|c|c|c|}
\hline \multirow{3}{*}{$\begin{array}{l}\text { Dog } \\
\text { no. }\end{array}$} & \multirow{2}{*}{\multicolumn{2}{|c|}{ Heart }} & & & \multicolumn{4}{|c|}{ Left ventricular end-diastolic } & & & & \\
\hline & & & \multicolumn{2}{|c|}{ Mean aortic pressure } & \multicolumn{2}{|c|}{ Pressure } & \multicolumn{2}{|c|}{ Volume } & \multicolumn{2}{|c|}{ Stroke volume } & \multicolumn{2}{|c|}{ Ejection fraction } \\
\hline & $\mathrm{C}$ & $\mathrm{E}$ & $\mathrm{C}$ & $\mathrm{E}$ & $\mathrm{C}$ & $\mathrm{E}$ & $\mathrm{C}$ & $\mathrm{E}$ & c & $\mathrm{E}$ & $\mathrm{C}$ & $\mathrm{E}$ \\
\hline & \multicolumn{2}{|c|}{$\mathrm{rate} / \mathrm{min}$} & \multicolumn{2}{|c|}{$m m \mathrm{Hg}$} & \multicolumn{2}{|c|}{$m m \mathrm{Hg}$} & \multicolumn{2}{|c|}{$m l / k g$} & \multicolumn{2}{|c|}{$\mathrm{ml} / \mathrm{kg}$} & \multicolumn{2}{|c|}{$\%$} \\
\hline \multicolumn{13}{|c|}{ Control group } \\
\hline 1 & 131 & 132 & 131 & 145 & 4 & 6 & 1.58 & 2.69 & 0.60 & 0.60 & 0.352 & 0.237 \\
\hline 2 & 120 & 140 & 130 & 155 & 10 & 10 & 1.96 & 2.30 & 0.56 & 0.65 & 0.285 & 0.280 \\
\hline 3 & 145 & 148 & 127 & 142 & 5 & 5 & 3.10 & 4.25 & 0.81 & 0.92 & 0.294 & 0.197 \\
\hline 4 & 180 & 184 & 139 & 158 & 3 & 3 & 2.14 & 4.10 & 0.52 & 0.91 & 0.236 & 0.278 \\
\hline 5 & 152 & 158 & 125 & 145 & 4 & 6 & 2.81 & 3.22 & 0.46 & 0.60 & 0.179 & 0.171 \\
\hline 6 & 140 & 137 & 134 & 155 & 6 & 6 & 2.64 & 2.40 & 0.61 & 0.69 & 0.206 & 0.282 \\
\hline 7 & 115 & 117 & 126 & 142 & 5 & 7 & 4.31 & 4.94 & 1.50 & 1.60 & 0.351 & 0.320 \\
\hline 8 & 129 & 132 & 137 & 148 & 4 & 6 & 4.10 & 4.92 & 1.07 & 1.22 & 0.260 & 0.252 \\
\hline Mean & 139 & 144 & 131 & 149 & 5.12 & 6.12 & 2.83 & 3.47 & 0.77 & 0.90 & 0.270 & 0.252 \\
\hline SEM & 8 & 6 & 1.9 & 2.3 & 0.76 & 0.69 & 0.35 & 0.38 & 0.13 & 0.12 & 0.020 & 0.014 \\
\hline$P$ value* & \multicolumn{2}{|c|}{$\therefore S$} & \multicolumn{2}{|c|}{$<0.001$} & \multicolumn{2}{|c|}{$<0.05$} & \multicolumn{2}{|c|}{$<0.01$} & \multicolumn{2}{|c|}{$<0.05$} & \multicolumn{2}{|c|}{$\mathrm{NS}$} \\
\hline \multicolumn{13}{|c|}{ Chronic ethanol group } \\
\hline 1 & 100 & 120 & 137 & 145 & 10 & 14 & 1.26 & 1.68 & 0.50 & 0.47 & 0.38 & 0.29 \\
\hline 2 & 133 & 127 & 141 & 162 & 6 & 9 & 1.59 & 2.05 & 0.46 & 0.55 & 0.29 & 0.27 \\
\hline 3 & 151 & 154 & 134 & 152 & 3 & 8 & 1.56 & 1.29 & 0.51 & 0.47 & 0.33 & 0.36 \\
\hline 4 & 90 & 128 & 142 & 161 & 11 & 14 & 1.58 & 1.69 & 0.44 & 0.49 & 0.28 & 0.29 \\
\hline 5 & 170 & 160 & 137 & 157 & 10 & 12 & 2.16 & 2.44 & 0.70 & 0.67 & 0.18 & 0.15 \\
\hline 6 & 124 & 122 & 126 & 134 & 9 & 12 & 2.26 & 2.32 & 0.50 & 0.51 & 0.29 & 0.27 \\
\hline 7 & 175 & 168 & 138 & 153 & 7 & 10 & 3.08 & 2.82 & 0.61 & 0.52 & 0.20 & 0.18 \\
\hline Mean & 134 & 139 & 136 & 152 & 8 & 11.28 & 1.92 & 2.04 & 0.53 & 0.53 & 0.279 & 0.259 \\
\hline SEM & 12 & 7 & 2.0 & 3.7 & 1.06 & 0.89 & 0.24 & 0.20 & 0.04 & 0.03 & 0.024 & 0.026 \\
\hline$P$ value* & \multicolumn{2}{|c|}{$\mathrm{NS}$} & \multicolumn{2}{|c|}{$<0.001$} & \multicolumn{2}{|c|}{$<0.01$} & \multicolumn{2}{|c|}{$\mathrm{NS}$} & \multicolumn{2}{|c|}{ NS } & \multicolumn{2}{|c|}{ NS } \\
\hline$P \ddagger$ & NS & & IS & & $<0.05$ & & $\mathrm{NS}$ & & $\mathrm{NS}$ & & NS & \\
\hline$P \S$ & & & & & & & & & & & & \\
\hline
\end{tabular}

$\mathrm{C}$, control data; E, during angiotensin.

* Paired $t$ test comparing control vs. angiotensin data.

$\ddagger$ Nonpaired $t$ test comparing control data in both groups.

$\S$ Nonpaired $t$ test for comparison of response to angiotensin response in controls vs. chronic ethanol group.

Plasma vitamins of the $B$ series and other major vitamins were present in similar concentrations at the end of the observation period in the control and alcoholic groups.

To evaluate the degree of intoxication in the chronic state after at least 6 mo of alcohol intake, samples for blood ethanol determinations were performed after acute ingestion on at least two occasions in each animal (41) and averaged $213 \pm 7 \mathrm{mg} / 100 \mathrm{ml}$. Alcohol administration was often associated with some degree of locomotor incoordination and occasional short periods of sleep.

Hemodynamic studies. At the onset of the study in the anesthetized state, mean heart rate and aortic pressure (Table II) were similar in both groups. However, in the chronic ethanol animals there was a significantly higher end-diastolic pressure despite a lower level of end-diastolic volume. Assessment of left ventricular function during afterload increments with angiotensin was undertaken with aortic diastolic pressure elevations of $16 \pm 1.1 \mathrm{~mm} \mathrm{Hg}$ in the control group and 17 $\pm 0.9 \mathrm{~mm} \mathrm{Hg}$ in the ethanol group. Stroke output increased modestly but significantly in the controls while no such increment occurred in the alcoholic animals. Ejection fraction was similar in both groups before and after angiotensin. Stroke work rose in the normals from $1.39 \pm 0.23$ to $1.81 \pm 0.21 \mathrm{~g}-\mathrm{m} / \mathrm{kg}$ but the response was significantly less in the experimental group ( $P$ $<0.01), 1.03 \pm 0.04$ to $1.11 \pm 0.07 \mathrm{~g}-\mathrm{m} / \mathrm{kg}$. The index of contractility revealed no significant difference between normals $(1.57 \pm 0.11)$ and alcoholics (1.36 \pm 0.10$)$ before angiotensin; there was a similar small decline in both groups during increased afterload. 


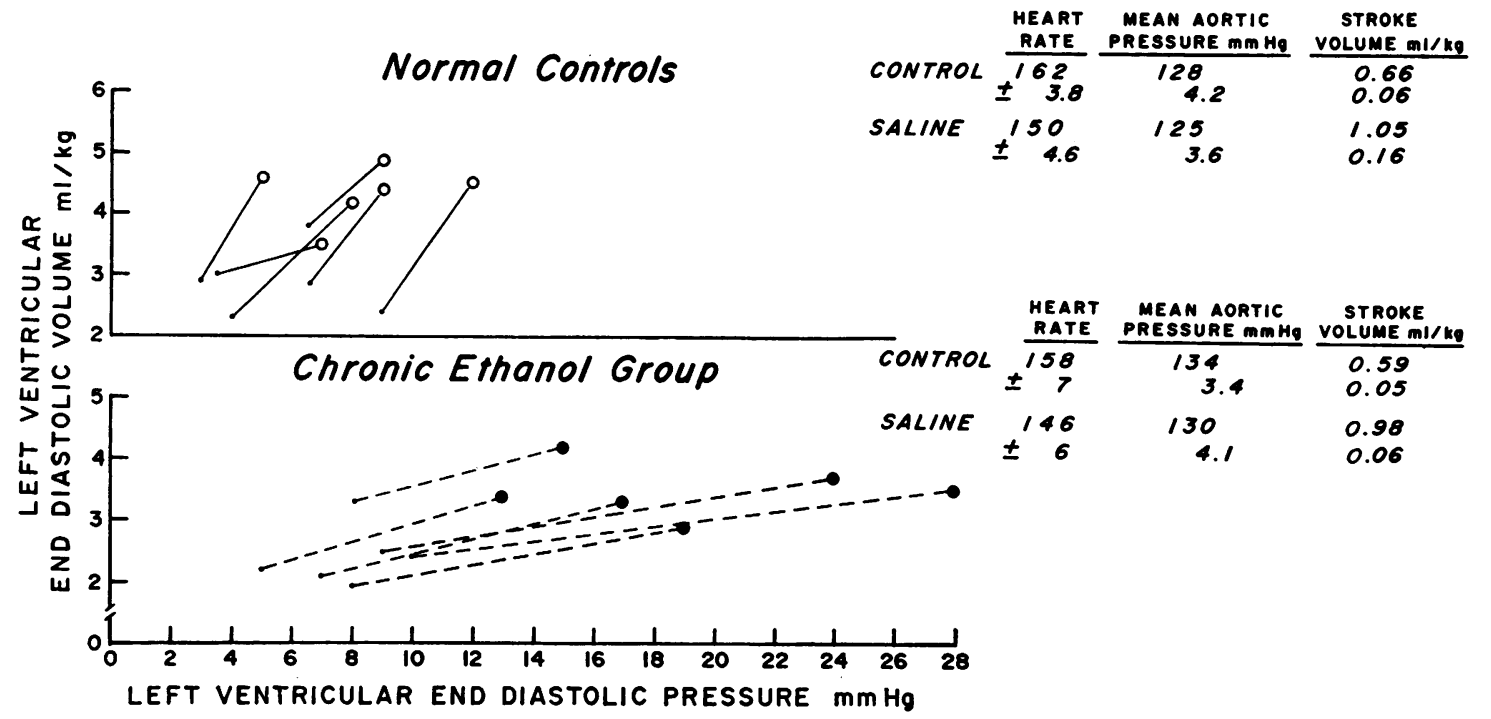

FIGURE 1 The response of the left ventricle to volume increments with normal saline was marked by a significantly higher end-diastolic pressure rise in animals on the chronic ethanol regimen, without significant differences in heart rate, aortic pressure, or stroke volume.

Normal controls exhibited a moderate rise of enddiastolic pressure and end-diastolic volume during angiotensin infusion. However, a significantly larger rise of end-diastolic pressure occurred in the ethanol group while the end-diastolic volume response was significantly less than in controls (Table II). This is presumably the basis for the reduced stroke volume.

The further evaluate the apparent altered stiffness of the ventricle, six of the normal animals and six of the ethanol group were infused with normal saline via a catheter in the left ventricle. At an infusion rate of $50 \mathrm{ml} / \mathrm{min}$ for 3-4 min, the normals generally exhibited a proportionate rise of left ventricular end-diastolic pressure and volume (Fig. 1). In the ethanol group, there was a significantly higher rise of end-diastolic pressure than in the normal $(P<0.01)$, despite an elevation of end-diastolic volume proportionate to controls. Heart rate declined and stroke volume rose similarly in both groups without a change in afterload, so that the significantly higher end-diastolic pressure in the experimental group would not appear to be related to these variables.

To examine a potential morphologic basis for the altered diastolic pressure-volume relations attributed to enhanced wall stiffness, apical sections of the left ventricle were examined histochemically. Staining with Alcian Blue showed distinct accumulation of a glycoprotein like material in the interstitium of the left ventricular wall in the ethanol group (Fig. 2). The degree of staining ranged from two to three plus, on a scale of zero to four. There was virtually no staining in the normal controls. Periodic acid-Schiff staining was slightly positive in the ethanol group.

Metabolic studies. Analyses of left ventricular lipids revealed an increment of triglyceride in the ethanol group (Table III), which appeared as fine cytoplasmic droplets on Oil Red O stain. Cholesterol, phospholipid, and free fatty acid levels were not significantly altered in the three layers of myocardium compared with the control group. It is noteworthy that at this stage of chronic alcoholism, the plasma lipid concentrations did not differ from control lipid levels, although transient increases of plasma triglyceride and cholesterol levels were present during the earlier months of the chronic ethanol period (Table IV).

There was no significant extraction of triglyceride, phospholipid, or cholesterol by the myocardium in the anesthetized state by controls or chronic ethanol animals. In addition to comparable arterial levels of blood glucose (Table I), myocardial uptake of glucose did not differ between the groups; $0.44 \pm 0.06 \mathrm{mM} / \mathrm{g} / \mathrm{min}$ in controls and $0.50 \pm 0.04 \mathrm{mM} / \mathrm{g} / \mathrm{min}$ in the ethanol group.

To explore the metabolic basis for the myocardial lipid alterations, $\left[1-{ }^{14} \mathrm{C}\right]$ oleic acid was administered by continuous infusion into the inferior vena cava. During the latter half of the $20 \mathrm{~min}$ infusion period when radioactivity in plasma had reached a plateau, the specific activity remained relatively constant in each dog. The mean plasma specific activity in controls was 59.1 $\pm 6.8 \times 10^{3} \mathrm{cpm} / \mu \mathrm{eq}$ of free fatty acid at $9 \mathrm{~min}$ and $60.7 \pm 8.1 \times 10^{3} \mathrm{cpm} / \mu \mathrm{eq}$ at $18 \mathrm{~min}$. In the ethanol group, 


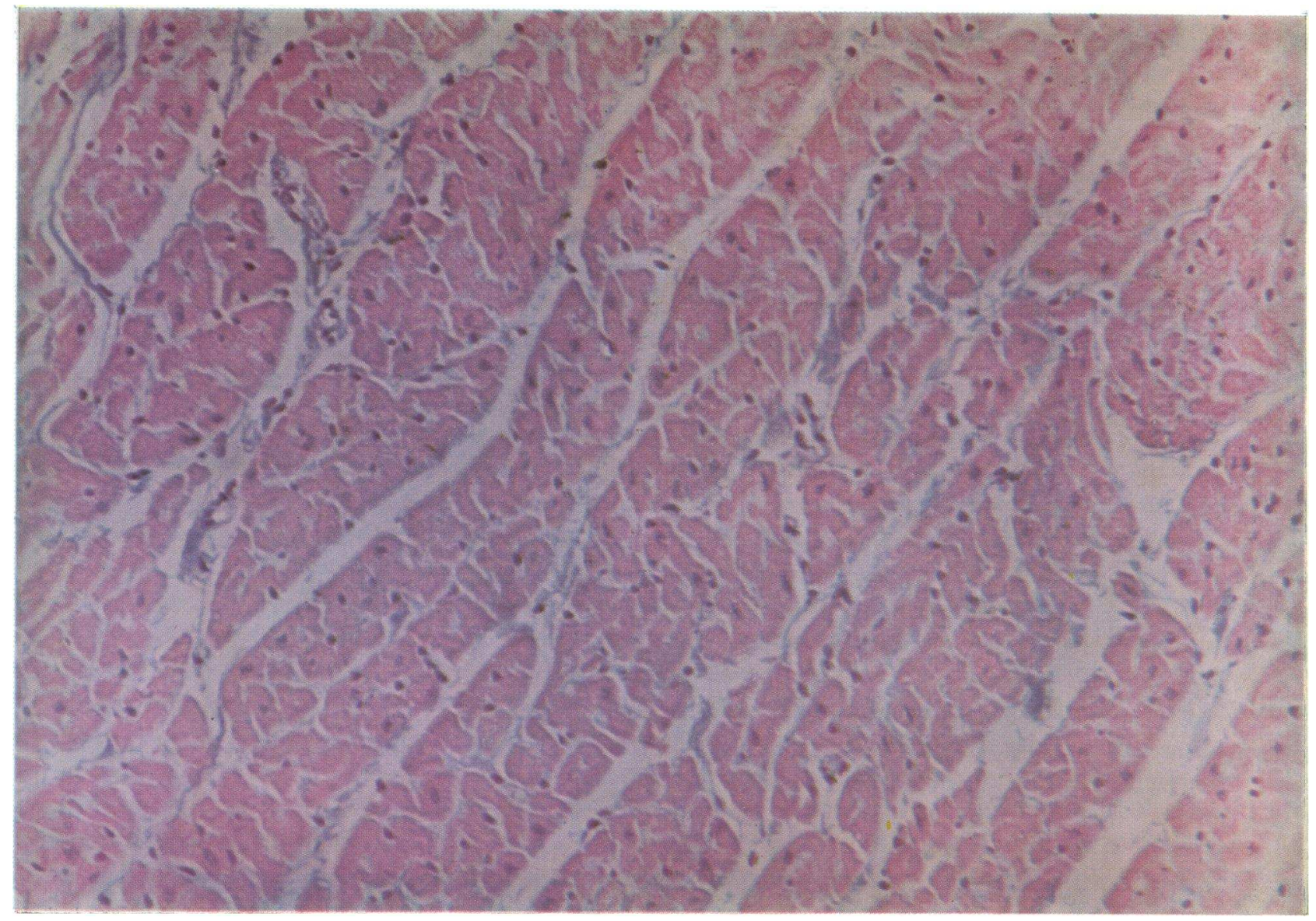

FIGURE 2 Accumulation of Alcian Blue-positive material in the ventricular interstitium is depicted in a representative animal from the chronic ethanol group.

the corresponding values were $61.8 \pm 7.1 \times 10^{3}$ and 61.5 $\pm 8.3 \times 10^{3} \mathrm{cpm} / \mu$ eq.

Free fatty acid uptake was calculated from the product of arterial and coronary venous plasma concentration differences and coronary plasma flow. Isotopic activities are expressed per $100 \mu \mathrm{Ci}$ of administered $\left[{ }^{14} \mathrm{C}\right]$ oleic acid. Uptake of total and isotopic fatty acid was similar in both groups; $0.082 \pm 0.009 \mu \mathrm{eq} / \mathrm{g} / \mathrm{min}$ and $8.25 \pm 1.9 \times 10^{3} \mathrm{cpm} / \mathrm{g} / \mathrm{min}$ respectively, in controls. In the ethanol animals uptake was respectively, $0.078 \pm 0.007 \mu \mathrm{eq} / \mathrm{g} / \mathrm{min}$ and $8.59 \pm 0.92 \times 10^{8} \mathrm{cpm} / \mathrm{g} /$ min. ${ }^{14} \mathrm{CO}_{2}$ production at $4,146 \pm 960 \mathrm{cpm} / \mathrm{g} / \mathrm{min}$, was significantly less in the myocardium of the alcohol group compared with the level of $7,080 \pm 639 \mathrm{cpm} / \mathrm{g}$ / min in controls $(P<0.02)$.

In terms of total isotopic counts in myocardium, there was no transmural gradient in the normals or alcoholic animals. Comparing the subendocardial layer as representative, the normal group had $20,406 \pm 1,244$ $\mathrm{cpm} / \mathrm{g}$ compared to $27,180 \pm 5,798$ in the ethanol ani- mals. This difference was not statistically significant. However, analysis of lipid classes revealed enhanced $\left[{ }^{14} \mathrm{C}\right]$ oleic acid incorporation in counts per minute per gram, into triglyceride but diminished phospholipid radioactivity in the ethanol group, significant for subendocardial layers (Table III). This was also reflected in greater isotopic activity of triglyceride as a percentage of total radioactivity in subendocardium, 18 $\pm 2.6 \%$ in controls vs. $45.2 \pm 7.8 \%$ for the experimental

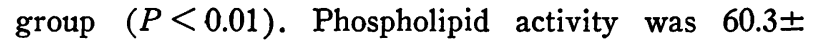
$5.0 \%$ in controls and was reduced to $35.1 \pm 5.2 \%$ after chronic use $(P<0.01)$. In comparing the ratio of phospholipid to triglyceride ${ }^{14} \mathrm{C}$ counts, there was a significant reduction in the ethanol group that was evident in all three layers. Specific activity of triglyceride tended to increase and for phospholipid to be reduced, but these changes were significant only for phospholipid in the subendocardial layer; $460 \pm 67$ in the ethanol group vs. $826 \pm 166$ in controls. Isotope levels in the free fatty acid and cholesterol fraction did 
TABLE III

Myocardial Incorporation of $\left[{ }^{14} \mathrm{C}\right]$ Oleic Acid

\begin{tabular}{|c|c|c|c|c|c|c|c|c|c|c|c|c|c|}
\hline & & \multicolumn{3}{|c|}{ Triglyceride } & \multicolumn{3}{|c|}{ Phospholipid } & \multicolumn{3}{|c|}{ Free fatty acid } & \multicolumn{3}{|c|}{ Cholesterol } \\
\hline & & $\mathrm{E}_{\mathrm{pi}} *$ & Miid & Subend. & Epi. & Mid & Subend. & Epi. & Mid & Subend. & Epi. & Mid & Subend. \\
\hline \multirow[t]{4}{*}{$\mathrm{cpm} / \mathrm{g}$} & $\mathrm{C}_{\ddagger}$ & 2,568 & 3,326 & 3,759 & 10,873 & 12,478 & 12,561 & 3,450 & 3,233 & 3,756 & 300 & 136 & 330 \\
\hline & & \pm 546 & 919 & 684 & 1,889 & 1,498 & 1,287 & 1,255 & 779 & 840 & 113 & 77 & 187 \\
\hline & $\mathrm{E}$ & 13,246 & 13,149 & $14,709 \S$ & 9,972 & 9,874 & $7,639 \S$ & 5,434 & 5,128 & 4,643 & 307 & 185 & 189 \\
\hline & & $\pm 5,094$ & 5,633 & 4,708 & 2,159 & 1,740 & 775 & 1,186 & 1,117 & 910 & 158 & 95 & 97 \\
\hline \multirow{4}{*}{$\begin{array}{l}\text { Lipid content, } \\
\quad \mu .1 / \mathrm{g}\end{array}$} & C & 1.89 & 1.74 & 2.23 & 16.5 & 15.3 & 15.2 & 10.2 & 9.8 & 10.6 & 3.41 & 3.90 & 3.8 \\
\hline & & \pm 0.40 & 0.51 & 0.81 & 1.4 & 1.9 & 1.0 & 1.1 & 1.0 & 1.1 & 0.51 & 0.37 & 0.31 \\
\hline & $\mathrm{E}$ & 3.90 & $3.95 \|$ & $4.82 \S$ & 16.9 & 16.6 & 16.6 & 11.75 & 12.0 & 12.0 & 3.98 & 3.82 & 3.78 \\
\hline & & \pm 0.82 & 0.61 & $0.78^{\circ}$ & 0.91 & 1.0 & 1.3 & 1.2 & 1.0 & 0.63 & 0.67 & 0.54 & 0.55 \\
\hline
\end{tabular}

* Epi, epicardium; mid, middle layers; subend., subendocardium.

$\ddagger$ Isotopic activity expressed as per $100 \mu$-Ci of administered [ $\left.{ }^{14} \mathrm{C}\right]$ oleic acid in six controls (C) and six ethanol animals (E).

$\$$ Significantly different from control at $P<0.05$ in unpaired $t$ test.

if Significantly different from control at $P<0.02$ in nonpaired $t$ test.

not differ from controls. However, the concentrations of lipid in the myocardium differed only in the triglyceride increment.

Morphologic studies revealed no inflammatory response in heart muscle to complicate the assessment of chemical composition. The changes in lipid metabolism were not accompanied by unequivocal abnormalities of mitochondrial structure on electron micrographs but accumulation of glycogen-type particles was evident. Lysosomal structures were relatively infrequent in both groups. Dilatation of the sarcoplasmic reticulum was a prominent feature in all animals receiving ethanol and the undifferentiated portion of the intercalated disk was similarly affected.

The distribution of potassium and sodium across the myocardial wall was found to be uniform in the control group from the outer to inner layers. However, in the ethanol group there was a significant transmural gradient of potassium ion, with reduction of approximately $10 \%$ in the endocardium (Table V). A sodium gain in left ventricular tissue was observed but a transmural gradient of this cation was less evident. Coronary blood flow by the ${ }^{85} \mathrm{Kr}$ clearance method in paired determinations was $94 \pm 5 \mathrm{ml} / 100 \mathrm{~g} / \mathrm{min}$ in the controls and $91.4 \pm 4.9 \mathrm{ml} / 100 \mathrm{~g} / \mathrm{min}$ in the experimental group, so that ischemia did not appear to be the basis for the cation alteration. In addition, longitudinal dissection of the left coronary arteries revealed no detectable encroachment on the arterial lumen or visible lesions of the endocardial surface. At the conclusion of the study, the weight of the left ventricle and septum in grams per kilogram of total body weight

TABLE IV

Course of Plasma Lipid Alterations

\begin{tabular}{|c|c|c|c|c|c|c|c|c|c|}
\hline & & \multicolumn{4}{|c|}{ Controls } & \multicolumn{4}{|c|}{ Ethanol groul) } \\
\hline & & \multirow[b]{2}{*}{ Initial } & \multirow[b]{2}{*}{ 4-6 Mo. } & \multicolumn{2}{|c|}{ Termination } & \multirow[b]{2}{*}{ Initial } & \multirow[b]{2}{*}{ 4-6 Mo. } & \multicolumn{2}{|c|}{ Termination } \\
\hline & & & & Conscious & $\begin{array}{l}\text { Anesthe- } \\
\text { tized }\end{array}$ & & & Conscious & $\begin{array}{l}\text { Anesthe- } \\
\text { tized }\end{array}$ \\
\hline \multicolumn{10}{|c|}{ Plasma lipids, $m M /$ liter } \\
\hline \multirow[t]{2}{*}{ Triglyceride } & & 0.38 & 0.35 & 0.37 & 0.39 & 0.42 & $1.39^{*}$ & 0.48 & $0.4 \Sigma$ \\
\hline & \pm & 0.03 & 0.06 & 0.04 & 0.05 & 0.05 & 0.11 & 0.06 & 0.08 \\
\hline \multirow[t]{2}{*}{ Phospholipid } & & 2.45 & 2.50 & 2.48 & 2.47 & 2.39 & 2.52 & 2.21 & 2.30 \\
\hline & \pm & 0.13 & 0.28 & 0.19 & 0.21 & 0.13 & 0.17 & 0.12 & 0.14 \\
\hline \multirow[t]{2}{*}{ Free fatty acid } & & 0.516 & $\mathrm{ND}_{+}^{+}$ & 0.590 & 0.465 & 0.528 & $\mathrm{ND}_{+}^{+}$ & 0.644 & 0.495 \\
\hline & \pm & 0.039 & & 0.051 & 0.038 & 0.043 & & 0.052 & 0.067 \\
\hline \multirow[t]{2}{*}{ Cholesterol } & & 3.27 & 3.13 & 3.09 & 3.15 & 3.43 & 4.12 & 3.47 & 3.46 \\
\hline & \pm & 0.18 & 0.23 & 0.27 & 0.24 & 0.25 & 0.29 & 0.31 & 0.33 \\
\hline
\end{tabular}

* Significantly different from initial values in ethanol group, $P<0.02$ by paired $t$ test.

$\ddagger$ No data available. 
TABLE V

Electrolyte and Water Composition of Myocardium

\begin{tabular}{|c|c|c|c|c|c|c|c|c|c|c|c|c|}
\hline & & \multicolumn{4}{|c|}{ Potassium } & \multicolumn{4}{|c|}{ Sodium } & \multicolumn{3}{|c|}{ Water } \\
\hline & & Plasma & Epi. & Mid & Endo. & Plasma & Epi. & Mid & Endo. & Epi. & Mid & Endo. \\
\hline & & meq/liter & & $\mu e q / g$ & & meq/liter & & $\mu e q / g$ & & & $\%$ & \\
\hline Normal, & & 3.78 & 62.0 & 61.2 & 61.2 & 145 & 31.9 & 32.1 & 31.8 & 78.7 & 78.9 & 78.1 \\
\hline$(n=8)$ & \pm & 0.14 & 1.5 & 1.2 & 1.1 & 2.0 & 2.5 & 2.0 & 2.3 & 0.78 & 0.81 & 0.73 \\
\hline Ethanol group, & & 4.05 & 61.3 & 58.2 & $55.1^{*}$ & 144 & $39.1 \ddagger$ & 38.2 & $40.0 \ddagger$ & 78.4 & 79.2 & 79.4 \\
\hline$(n=6)$ & \pm & 0.18 & 1.4 & 1.1 & 0.8 & 2.8 & 2.0 & 2.5 & 2.7 & 0.96 & 0.39 & 0.60 \\
\hline
\end{tabular}

* $P<0.01$ in nonpaired $t$ test compared with corresponding area in controls.

$\ddagger P<0.05$.

was $4.7 \pm 0.19$ in the normal group and $4.47 \pm 0.17$ in the ethanol group.

From the original group of 13 animals, 4 died suddenly. This did not appear related to lethal intoxication from ethanol since the deaths occurred some hours removed in time from the last feeding. Myocardial tissue was sampled between 1-12 $\mathrm{h}$ after the death of the four. It is noteworthy that these four animals revealed increases in myocardial triglyceride to $27.9 \pm 5.3$ $\mu \mathrm{M} / \mathrm{g}$ in the ventricular sample, substantially higher than in the cold-arrested heart, which may have been related to terminal events. Phospholipid content was reduced to $13.1 \pm 4.3 \mu \mathrm{M} / \mathrm{g}$. There was a substantial rise in free fatty acid concentrations, presumably related to phospholipid hydrolysis in the postmortem period. Cation distribution also differed from that of animals whose hearts were cold arrested, with $\mathrm{K}^{+}$ higher in the mid- $(72.0 \pm 5.6 \mu \mathrm{eq} / \mathrm{g})$ and endocardial (67.2 \pm 4.5$)$ regions without altered water content. Thus, the composition of hearts removed under experimental conditions can qualitatively differ from postmortem data. One of the four spontaneous deaths, after $3 \mathrm{yr}$ the longest term alcoholic, had mural thrombi in both ventricles with emboli in the pulmonary and systemic circulations.

\section{DISCUSSION}

This animal model of chronic alcoholism quantitatively approximates the disease in ambulatory human alcoholics, with a reported average consumption of $36 \%$ of total calories as ethanol and no evidence of nutrient deficit in the majority (4). Although abnormal levels of thiamine and the other vitamins of the B series may be observed in the late stages of alcoholism (42), only a deficiency of the former gives rise to a specific entity-the beri beri syndrome (43). The pathophysiology observed in these chronic alcoholic animals receiving supplementary vitamins is apparently independent of a vitamin deficit, assuming that normal blood levels are indicative of normal tissue concentrations (42). That protein intake was sufficient to meet minimum requirements for the adult dog (7), is supported by the fact that the experimental group maintained body weight, serum proteins, and hematocrit. Moreover, the histologic changes of experimental protein deficiency, which may include inflammatory cell infiltrates and hydropic degeneration of myocardial fibers, were not present (44).

These experiments would ideally have been accomplished with each animal as his own control. However, the amount of cardiac tissue required for the analytical studies and the number of vessels catheterized to determine arteriovenous differences, coronary blood flow, intracardiac conduction times (unpublished studies), as well as left ventricular volumes and pressures made this unfeasible. Long-term instrumentation for hemodynamic studies in the unanesthetized state would have been desirable but quite difficult to achieve in animals maintained for several years.

The hemodynamic findings in these animals resemble those observed in human alcoholics with preclinical cardiac malfunction (45-47). During increased afterload the elevation of filling pressure was significantly higher than in control animals. While stroke volume rose in normals, no increment occurred in the ethanol group presumably related to the lack of end-diastolic volume increase. To evaluate whether the latter was due to diminished myocardial compliance, the filling pressure response to volume expansion during saline infusion was assessed. A significantly greater rise of end-diastolic pressure in the animals receiving ethanol compared with normal controls, supports the interpretation of increased diastolic stiffness of left ventricular muscle in the experimental group.

Since left ventricular weights were similar to control hearts, hypertrophy would not seem to contribute to this functional abnormality. Elasticity of muscle has been attributed predominantly to extracellular struc- 
tures (48) but the relative importance of collagen and glycoprotein in this regard is unknown. Since the former did not appear to be present in increased quantity when tissue was stained with trichrome, histochemical stains were used to assess the potential accumulation of glycoprotein and revealed Alcian Blue positive material. Support for the view that increments of extracellular glycoprotein can diminish diastolic compliance is derived from observations in experimental diabetes where accumulation of periodic acidSchiff-positive material in the myocardial interstitium was associated with enhanced stiffness (49). In addition, increments of noncollagen material largely limited to the intercellular space may occur in the early stages of amyloid heart disease, a situation which ultimately limits diastolic filling $(50,51)$. While alteration of other myocardial elements such as sarcolemma could contribute to the compliance change in alcoholic animals, the accumulation of glycoprotein in the intercellular space suggests a probable basis for enhanced myocardial stiffness. The glycoprotein composition has not been characterized but presumably has a high content of hyaluronic acid since Alcian Blue has an affinity for acid mucopolysaccharide (52).

A previous hemodynamic study of chronic ethanol administration in the rat has shown a significant decrease in "potential ventricular force" (53). In contrast, a definite abnormality of ventricular function was not found in the same species fed less ethanol, $15 \%$ by volume (54), compared to $25 \%$ in the previous series (53). In addition, an important methodologic difference existed, in that ventricular function was tested at the upmost segment of the ascending portion of the function curve (53), so that the ventricle was not stressed to the same extent in the Lochner study. Since caloric equivalents were not provided it is difficult to compare these data with the present study; moreover, species difference may exist. In a recent study of dogs fed ethanol in a daily quantity similar to that of the present study, but for a 14-wk period, no hemodynamic abnormality was observed (55). This is consistent with the view that duration of ingestion is an important determinant.

The importance of chronicity is also evident in the reported failure to find morphologic abnormalities of cardiac cell organelles in animals ingesting ethanol for 1-3 mo $(56,57)$. Dilatation of the sarcoplasmic reticulum and intercalated disk were the only unequivocal structural abnormalities in the relatively well-nourished animals in this current report, findings also observed in two studies of patients with alcoholic cardiomyopathy $(58,59)$. It is problematic whether the extensive abnormalities of myofibrils and mitochondria reported earlier are due solely to toxicity or to coexistent nu- tritional deficiency, cobalt excess, or other complications (60-62).

Comparison of the myocardial metabolism of $\left[1{ }^{14} \mathrm{C}\right]-$ oleic acid with controls during a steady state was facilitated by the comparability of the plasma specific activity, indicating that labeled oleate was diluted in a similar size plasma free fatty acid pool in the control and experimental groups. In addition, hemodynamic interventions before the metabolic study did not appear to influence myocardial distribution of $\left[{ }^{14} \mathrm{C}\right]$ oleate since incorporation in controls was predominantly in phospholipid, in agreement with a prior study from this laboratory without such intervention (34). Moreover, in two of the chronic ethanol animals without evalution of ventricular function the distribution of labeled fatty acid was similar to that of animals with prior hemodynamic studies.

In the chronic alcohol state no significant uptake of triglyceride was observed and free fatty acid uptake did not differ significantly from controls but ${ }^{14} \mathrm{CO}_{2}$ production was decreased. Reduced oxidation may be secondary to diminished activity of rate-limiting enzymes in the citric acid cycle (63), demonstrated after chronic ethanol use (55). A resultant enhanced availability of acyl-CoA, perhaps associated with enhanced glycerol acyltransferase activity (64) may account for triglyceride accumulation. All three myocardial layers exhibited an increased isotope incorporation in triglyceride, significant for the subendocardium; a role for altered lipase activity is not excluded. The finding that total tissue isotopic activity was not significantly enhanced was in part due to diminished incorporation into phospholipid as well as the relatively large variance of isotope activity in the ethanol group.

De novo synthesis of triglyceride may also be contributory to accumulation of this lipid. but this is not readily assessed in the intact animal due to early recvcling of $\left[{ }^{14} \mathrm{C}\right]$ acetate in plasma as labeled fatty acid. Moreover, acetate incorporation normally contributes in a minor way to triglyceride synthesis in isolated heart (65) and enhanced activity of this pathway has been observed only during hypoxia (66).

Incornoration of labeled fatty acid into phospholipid was sufficiently reduced in subendocardium to diminish specific activity, despite the observation that the mvocardial $\left[{ }^{14} \mathrm{C}\right]$ free fatty acid fraction was not reduced. This may represent interference with transacvlation in the phospholipid molecule. In addition, preliminary data on labeled lipid intermediates assayed by thin-layer chromatography (unpublished studies) have revealed a threefold rise in myocardial content of $\left[1,2-{ }^{11} \mathrm{C}\right]$ diglyceride in the animals receiving ethanol, associated with normal levels of radioactive phosphatidic acid and monoglyceride. Apparently, the labeled fatty acid in 
diglyceride has limited accessability to phospholipid by transacylation or through a cytidine disphosphate diacylglvcerol transferase reaction. A recent report of diminished arachidonate in cardiac phospholipids of the ethanol-treated rat supports the view that substantial fatty acid compositional changes occur in this lipid class after chronic alcohol use (67).

The reduction of myocardial potassium and gain of sodium appears to be based on changes in cell cation composition, since tissue water was not increased as would be expected if interstitial edema was responsible; the latter was also not evident by light and electron microscopy. This cation alteration appeared unrelated to ischemia since there were no occlusive lesions of the extra or intramural coronary arteries while myocardial blood flow and mitochondria appeared normal. Of interest is the fact that the subendocardium exhibited the largest cation change as well as the more prominent changes in triglyceride and phospholipid metabolism. The interrelationship of altered lipid metabolism and cation gradients as well as the relative pathogenetic roles of ethanol and its first metabolite, acetaldehyde, remain to be elucidated.

\section{ACKNOWLEDGMENTS}

The authors gratefully acknowledge the technical assistance of Mrs. Bess Jenkins, Mr. Emil Wolf, and Mrs. Frances Herdman, and the secretarial services rendered by Mrs. Anne Binetti and Mrs. Audrey Brown.

This investigation was supported in part by the National Institute on Alcohol Abuse and Alcoholism Research Grant AA00242 and National Heart and Lung Institute Postgraduate Training Grant HL 05510.

\section{REFERENCES}

1. Ferrans, V. J. 1966. Alcoholic cardiomyopathy. Am. J. Med. Sci. 252: 89-104.

2. Regan. T. J. 1971. Ethyl alcohol and the heart. Circulation. 44: 957-963.

3. Schenk, E. A., and J. Cohen. 1970. The heart in chronic alcoholism. Clinical and pathological findings. Pathol. Microbiol. 35: 96-104.

4. Neville, J. N., J. A. Eagles, G. Sampson, and R. E. Olson. 1968. The nutritional status of alcoholics. Am. J. Clin. Nutr. 21: 1329-1340.

5. Ferrans, V. J., R. G. Hibbs, D. G. Weilhaecher, W. C. Black, J. J. Walsh, and G. E. Burch. 1965. Alcoholic cardiomyopathy: a histochemical study. Am. Heart J. 69: 748-765.

6. Marciniak, M., S. Gudbjarnason, and T. A. Bruce. 1968. The effect of chronic alcohol administration on enzyme profile and glyceride content of heart muscle, brain and liver. Proc. Soc. Exp. Biol. Med. 128: 10211025.

7. Nutrient Requirements of Dogs: A Report of the Committee on Animal Nutrition. 1962. National Academy of Sciences-National Research Council 989: no. 8. Washington, D. C.
8. Kelley, T. J. 1965. Improved method for microdetermination of fatty acids. Anal. Chem. 37: 1078-1079.

9. Kessler, G., and H. Lederer. 1966. Fluorometric measurement of triglycerides. Automation Analytical Chemistry, Technicon Symmosium, New York. Mediad, Inc., White Plains, N. Y. 341-344.

10. Barlett, G. 1959. Phosphorous assay in column chromatography. J. Biol. Chem. 24: 466-468.

11. Levine, J. B., and B. Zak. 1964. Automated determination of serum total cholesterol. Clin. Chim. Acta. 10: 381-384.

12. Hill, J. B., and G. Kessler. 1961. An automated determination of glucose utilizing a glucose oxidase peroxidase system. J. Lab. Clin. Med. 57: 970-980.

13. Failing, J. F., Jr., M. W. Buckley, and B. Zak. 1960. Automatic determination of serum proteins. Tech. Bull. Regist. Med. Technol. 29 : 205-210.

14. Nishi, H. H., and A. Rhodes. 1966. An automated procedure for the determination of albumin in human serum. The 3rd Technicon Symposium, London. Mediad, Inc. White Plains, N. Y. 321-324.

15. Baker, H., and O. Frank. 1968. Clinical Vitaminology. Methods and Interpretation. Interscience Puhlishers. Div. of John Wiley \& Sons, Inc., New York. 238 pp.

16. Regan, T. J., A. J. Passannante, M. I. Khan, H. A. Oldewurtel, and M. U. Jesrani. 1971. Influence of scar on left ventricular performance at the onset of myocardial ischemia: shock versus heart failure. J. Clin. Invest. 50: 534-542.

17. Keroes, J., and E. Rapaport. 1972. Ventricular volume measurement in the awake dog using implanted thermistor beads. J. Appl. Physiol. 32: 404-408.

18. Nash, C. B., F. Davis, and R. A. Woodbury. 1956. Cardiovascular effects of anesthetic doses of pentobarbital sodium. Am. J. Phusiol. 185: 107-112.

19. Levinson, G. E., M. J. Frank. M. Nadimi, and M. Braunstein. 1967. Studies of cardiopulmonary blood volume. Measurement of left ventricular volume by dye dilution. Circulation. 35 : 1038-1048.

20. Hngenholtz, P. G., H. R. Wagner, and H. Sandler. 1968. The in vivo determination of left ventricular volume: comparison of the fiber ontic-indicator dilution and the angiocardiographic methods. Circulation. 37: 489-508.

21. Swan, H., V. Ganz, J. C. Wallace, and K. Tamura. 1968. Left ventricular end-diastolic volume (EDV) by angiographic and thermal methods in a single diastole. Circulation. 38 (Sunpl. 6) : 193. (Abstr.)

22. Frank, M. J., P. E. Cundy, Jr., T. L. Crews, and W. J. Lewis, III. 1971. Comparison of left ventricular volumes by single-plane cineangiogranhy and by indicator dilution. J. Lab. Clin. Med. $77:$ 580-593.

23. Swan. H. J. C., and W. Beck. 1960. Ventricular nonmixing as a source of error in the estimation of ventricular volume by the indicator-dilution technic. Circ. Res. 8: 989-998.

24. Maseri, A., and Y. Enson. 1968. Mixing in the right ventricle and pulmonary artery in man: evalution of ventricular volume measurements from indicator washout curves. J. Clin. Invest. 47 : 848-859.

25. Newman. E. V., M. Merrell, A. Genecin. C. Monge, W. R. Milnor, and W. P. McKeever. 1951. The dye dilution method for describing the central circulation. 
An analysis of factors shaping the time-concentration curves. Circulation. 4: 735-746.

26. Carleton, R. A., A. F. Bowyer, and J. S. Graettinger. 1966. Overestimation of left ventricular volume by the indicator dilution technique. Circ. Res. 18: 248-256.

27. Holt, J. P., E. A. Rhode, and H. Kines. 1968. Ventricular volumes and body weight in mammals. $A m$. J. Physiol. 215: 704-715.

28. Frank, M. J., and G. E. Levinson. 1968. An index of the contractile state of the myocardium in man. J. Clin. invest. 47 : 1615-1626.

29. Ross, J., Jr., and E. Braunwald. 1964. The study of left ventricular function in man by increasing resistance of ventricular ejection with angiotensin. Circulation. 29 : 739-749.

30. Regan, T. J., G. E. Levinson, H. A. Oldewurtel, M. J. Frank, A. B. Weisse, and C. B. Moschos. 1969. Ventricular function in noncardiacs with alcoholic fatty liver: the role of ethanol in the production of cardiomyopathy. J. Clin. Invest. 48: 397-407.

31. Frank, M. J., M. Nadimi, P. Casanegra, P. Stein, and R. Pekaar. 1970. Effect of angiotensin on myocardial function. Am. J. Physiol. 218: 1267-1272.

32. O'Rourke, R. A., B. Pegram, and V. S. Bishop. 1972. Variable effect of angiotensin infusion on left ventricular function. Cardiovasc. Res. 6: 240-247.

33. Harman, M. A., A. Markov, P. H. Lehan, H. A. Oldewurtel, and T. J. Regan. 1966. Coronary blood flow measurements in the presence of arterial obstruction. Circ. Res. 19: 632-637.

34. Regan, T. J., A. J. Passannante, H. A. Oldewurtel, W. M. Burke, and P. O. Ettinger. 1972. Cardiac metabolism of triglyceride, acetate and oleate early after 1-norepinephrine injury. J. Appl. Physiol. 33: 325-330.

35. Snyder, F., and P. Godfrey. 1961. Collecting $\mathrm{C}^{14} \mathrm{O}_{2}$ in a warburg flask for subsequent scintillation counting. J. Lipid Res. 2: 195.

36. Regan, T. J., A. Markov, M. I. Khan, M. U. Jesrani, H. A. Oldewurtel, and P. O. Ettinger. 1972. Myocardial ion and lipid changes during ischemia and catecholamine induced necrosis: relation to regional blood flow. In Myocardiology: Recent Advances in Studies on Cardiac Structure and Metabolism. E. Bajusz and G. Rona, editors. University Park Press, Baltimore, Md. 1: 656-664.

37. Malins, D. C., and H. K. Mangold. 1960. Analysis of complex lipid mixtures by thin-layer chromatography and complimentary methods. J. Am. Oil Chem. Soc. 37: 576-578.

38. Dixon, W. J., and F. J. Massey, Jr. 1957. Introduction to Statistical Analysis. McGraw-Hill Book Co., New York. 2nd edition. 488 pp.

39. Luna, L. G. 1968. Manual of Histologic Staining Methods of the Armed Forces Institute of Pathology. McGraw-Hill Book Co., New York. 3rd edition. 258 pp.

40. Pearse, A. G. E. 1968. Histochemistry: Theoretical and Applied. Little Brown \& Co., Boston. 3rd edition. 1: 759 pp.

41. Roach, M. K., and P. J. Creaven. 1968. A micro-method for the determination of acetaldehyde and ethanol in blood. Clin. Chim. Acta. 21 : 275-278.

42. Leevy, C. M., H. Baker, O. Ten-Hove, O. Frank, and G. R. Cherrick. 1965. B-complex vitamins in liver disease of the alcoholic. Am. J. Clin. Nutr. 16: 339-346.
43. Fowler, N. O. 1973. The secondary cardiomyopathies. In Myocardial Diseases. Grune \& Stratton, Inc., New York. 337-359.

44. Chauhan, S., N. C. Nayak, and V. Ramalingaswami. 196j. The heart and skeletal muscle in experimental protein malnutrition in Khesus monkeys. J. Pathol. Bacteriol. 90 : 301-309.

45. Gould, L., M. Shariff, and M. DiLieto. 1969. Cardiac hemodynamics in alcoholic patients with chronic liver disease and presystolic gallop. J. Clin. Invest. 48: 860868.

46. Spodick, D. H., V. M. Pigott, and R. Chirife. 1972. Preclinical cardiac malfunction in chronic alcoholism. Comparison with matched normal controls and with alcoholic cardiomyopathy. N. Engl. J. Med. 287: 677680.

47. Asokan, S. K., M. J. Frank, and A. C. Witham. 1972. Cardiomyopathy without cardiomegaly in alcoholics. Am. Heart J. 84 : 13-18.

48. Brady, A. J. 1968. Active state in cardiac muscle. Physiol. Rev. 48: 570-600.

49. Regan, T. J., M. I. Khan, M. U. Jesrani, H. A. Oldewurtel, and P. O. Ettinger. 1973. Alterations of myocardial function and metabolism in chronic diabetes mellitus. In Myocardial Metabolism. N. S. Dhalla, editor. University Park Press, Baltimore, Md. 31 : 169-178.

50. Buja, L. M., N. B. Khoi, and W. C. Roberts. 1970. Clinically significant cardiac amyloidosis. Am. J. Cardiol. 26: 394-405.

51. Brigden, W. 1964. Cardiac amyloidosis. Prog. Cardiovasc. Dis. $7: 142-150$.

52. Zuguibe, F. T. 1970. The carbohydrates. In Diagnostic Histochemistry. F. T. Zuguibe, editor. The C. V. Mosby Co., St. Louis, Mo. 61-92.

53. Maines. J. E., III, and E. E. Aldinger. 1967. Myocardial depression accompanying chronic consumption of alcohol. Am. Heart J. 73: 55-63.

54. Lochner, A., R. Cowley, and A. J. Brink. 1969. Effect of ethanol on metabolism and function of perfused rat heart. Am. Heart J. 78: 770-780.

55. Pachinger, O. M., H. Tillmanns, J. C. Mao, J.-M. Fauvel, and R. J. Bing. 1973. The effect of prolonged administration of ethanol on cardiac metabolism and performance in the dog. J. Clin. Invest. 52: 2690-2696.

56. Hall, J. L., and D. T. Rowlands, Jr. 1970. Cardiotoxicity of alcohol. An electron microscopic study in the rat. Am. J. Pathol. 60: 153-160.

57. Gvozkják, A., V. Bada, F. Kruty, T. R. Niederland, and J. Gvozdják. 1973. Chronic effect of ethanol on the metabolism of myocardium. Biochem. Pharmacol. 22: 1807-1811.

58. Bulloch, R. T., M. B. Pearce, M. L. Murphy, B. J. Jenkins, and J. L. Davis. 1972. Myocardial lesions in idiopathic and alcoholic cardiomyopathy. Study by ventricular septal biopsy. Am. J. Cardiol. 29: 15-25.

59. Ferrans, V. J., W. C. Roberts, G. I. Shugoll, R. A. Massumi, and N. Ali. 1973. Plasma membrane extensions in intercalated discs of human myocardium and their relationship to partial dissociations of the discs. J. Mol. Cell. Cardiol. 5: 161-169.

60. Hibbs, R. G., V. J. Ferrans, W. C. Black, D. G. Weilbaecher, J. J. Walsh, and G. E. Burch. 1965. Am. Heart J. 69: 766-779.

61. Alexander, C. S. 1966. Idiopathic heart disease. II. 
Electron microscopic examination of myocardial biopsy specimens in alcoholic heart disease. Am. J. Med. 41: 229-234.

62. Auger, C., and J. Chenard. 1967. Quebec beer-drinkers' cardiomyopathy: ultrastructural changes in one case. Can. Med. Assoc. J. 97 : 916-921.

63. Neely, J. R., M. J. Rovetto, and J. F. Oram. 1972. Myocardial utilization of carbohydrate and lipids. Prog. Cardiovasc. Dis. 15: 289-329.

64. Joly, J-G., L. Feinman, H. Ishii, and C. S. Lieber. 1973. Effect of chronic ethanol feeding on hepatic micro- somal glycerophosphate acyl transferase activity. $J$. Lipid Res. 14 : 337-343.

65. Whereat, A. F., and M. W. Orishimo. 1969. Effects of fasting and diabetes on fatty acid synthesis by heart mitochondria. Am. J. Physiol. 217 : 998-1003.

66. Gloster, J., and P. Harris. 1972. Effect of anaerobiosis on the incorporation of $\left({ }^{14} \mathrm{C}\right)$ acetate into lipid in the perfused rat heart. J. Mol. Cell. Cardiol. 4 : 213-228.

67. Reitz, R. C., E. Helsabeck, and D. P. Mason. 1973. Effects of chronic alcohol ingestion on the fatty acid composition of the heart. Lipids. 8: 80-84. 